\title{
Applying TRIZ Systematic Innovation Method to Improve Urinals
}

\author{
Chia-Pao Chang \\ Department of Industrial Engineering and Management, \\ National Chin-Yi University of Technology \\ Taichung, Taiwan, R.O.C. \\ chiapc@ncut.edu.tw \\ Ying-Hsiang Lin \\ Department of Industrial Education and Technology, \\ National Changhua University of Education \\ Changhua, Taiwan, R.O.C. \\ 3150316@yahoo.com.tw
}

\begin{abstract}
The common urinal flusher, whether the button switch type or infrared detection induction, due to the water hole in the system by flushing it into the water column outflow, which cannot be evenly distributed in the urinal, resulting in poor cleaning effect. Furthermore, when a large amount of water washed down by the water hole to the urinal, due to the proliferation area of the water column is not enough, but will make the odor. The discomfort caused by toilet, and a lot of punch water will cause waste of water resources. In this study we apply TRIZ Systematic Innovation Method includes: 9-Windows, Contradiction Matrix, and 40 Inventive Principles to solve the problem. The final result shows that the improved urinal flusher devices can be used to adjust the angle to change the spraying angle of the wall of the urinal. There are two features of our design. (1) Water-saving efficiency up to $75 \%$, each flush amount reduced from $1200 \mathrm{ml}$ to $300 \mathrm{ml}(2)$ Adjustable nozzle angle to increase the rinsing area.
\end{abstract}

Keywords-component; urinal; TRIZ ;9-Windows; contradiction matrix; 40 inventive principles.

\section{INTRODUCTION}

According to statistical data of Central Weather Bureau, Taiwan's annual total rainfall is about 2500mm ranked 3rd of the worth, but actually be used amount only 26\% (about 650mm) . Therefore, It has become the 18th water shortages country. People waste water, will have to face water shortages in the future. With the environmental protection and energy conservation concept increasing, People begin to realize the importance of water resources in recent years. There are so many water resources wasted around us, using a urinal is a significant example.

Problem solving process is the search for the innovative and creative solution. There are several ways to solve industrial problems during development of product, and manufacturing processes [1]. We applied TRIZ to solve many household problems such as walkers, drainers, and got satisfied solutions.

\author{
Chien-Yu Lu \\ Department of Industrial Education and Technology, \\ National Changhua University of Education \\ Changhua, Taiwan, R.O.C. \\ lcy@ cc.ncue.edu.tw
}

\begin{abstract}
II. RESEARCH METHOD
After the observation of many invention-related issues in the innovation process, Altshuller summarized the first breakthrough discovery, the technical contradiction. The so called technical contradiction means, when he innovator attempts to improve a technical system parameter A, it will result in the worsening of parameter B. For example, when reducing the product weight can make the product lighter and easier to carry, it will also make the product thinner and more fragile. When using better replacement material, the cost will increase. The TRIZ innovative invention is a new way of thinking which is beyond the contradiction to allow the two contradictory parameters to develop in the positive direction.
\end{abstract}

\section{(1) Research process}

As shown in Figure 1, after identifying the issues of an object, we need to find out the issues and the technical contradictions. After learning the technical contradictions, we then can develop the $39 \times 39$ contradiction matrix in search of the 40 inventive principles that can possibly solve the technical contradiction. Next, the feasible 40 inventive thinking solutions and logic thinking are employed to consider the listed programs and select the most appropriate solution to solve the problem. 


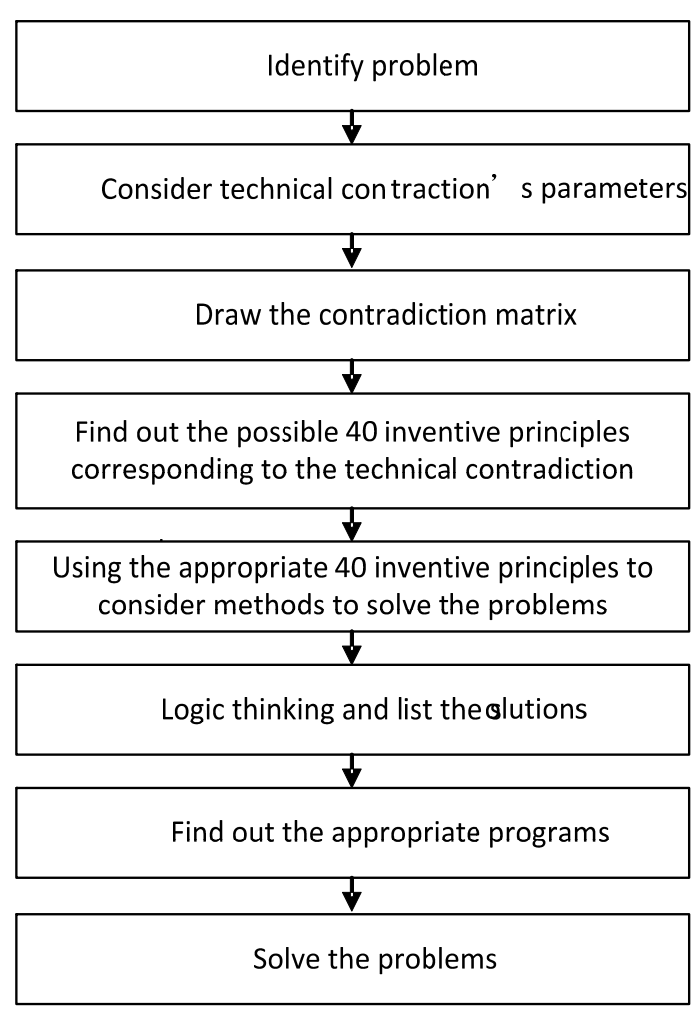

(2) 9-Windows

Figure 1. Research flowchart

A number of techniques that can help to define the problem and understand the context of the solution have been developed. One such technique is referred to as a '9-Box' or '9-Windows'. This technique places the system that is being worked with the context of its sub and super-systems and in the past and possible future embodiments of the system in question. The idea is to zoom out of the present context of the system and understand the broader context. Such a technique can bring resources and possibilities into play that were not recognized before. [2]

\section{(3) Contradiction matrix}

Altshuller observed each technical contradiction and developed a system accordingly. The first system regarding innovation and invention is known as the contradiction matrix. When studying patents, he would confirm and summed up the technical contradictions and the applied innovative inventive principles for this patent. Based on the summaries of a large number of patents, he summed up 39 engineering parameters and 40 innovative inventive principles, and developed the $39 \times 39$ matrix , which is a matrix using $i$ to represent the improved characteristic and $j$ to represent the avoidance of worsening result. Each box grid represents a type of inventive problems, and each inventive problem has corresponding $\mathrm{i}$ and $\mathrm{j}$ coordinates. In the box grid of specific $i$ and $j$, there are identification codes of inventive principles to solve the problems. [3] , [4].
(4) 40 inventive principles

40 principles provide TRIZ users a way of thinking from principle to application. Each inventive principle is a simple basic concept, and the derived thoughts from the principle can cover a wide range. Different principles' layers and details can produce different architectures and contents. Each principle and thought can empower the innovator with new answers, "think about each principle and then find out the answer" [5], [6].

\section{ACTUAL CASE OF IMPROVED DESIGN}

(1) Technical contradiction of the improvement case

The main purpose is to improve the urinal design to reduce wasting water resources and increase the efficiency of the urinal flusher. The best method to realize this purpose is to increase the flush area and decrease water washing amount each flush. However, change the urinal flusher will affect the structure of urinal. Such changes are not expected, therefore the existing technical contradictions are: the technical contradiction 1: "system complexity" Vs "increase the flush area" and the technical contradiction 2: "system complexity” Vs “water pressure”.

\section{(2) Development of contradiction matrix}

As shown in Table 1, the appropriate i (improved characteristic) and j (avoidance of worsening result) are found in the matrix. No.36 column is "system complexity", while No. 6 row is "Area of stationary object", No. 11 row is "Stress or pressure". The table presents Contradiction 1 "system complexity" and "Area of stationary object", Contradiction 2 "system complexity" and "Stress or pressure”, the box grids of intersecting columns and rows represent the principles that can be used to solve the existing contractions.

According to the analysis of the feasible improvement concepts and programs based on the recommended principles, it is preliminarily concluded by assessment that No. 1 principle "segmentation”, No. 18 principle "mechanical vibration”, No. 19 principle "periodic action”, No. 35 principle "parameter changes" , No. 36 principle "phase transitions" are the best suggestions that can be improved by current technologies.

Contents of No. 1 principle "segmentation: Divide a system into separate parts or sections; Make a system easy to put together or take apart; Increase the amount of segmentation.

Contents of No. 19 principle "periodic action": Replace continuous actions with periodic or pulsating actions; If an action is already periodic, change the periodic magnitude or frequency to suit external requirements; Use gaps between actions to perform different useful actions.

Contents of No. 35 principle "parameter changes: Change an objects physical state; Change concentration or consistency; Change the degree of flexibility; Change the temperature; Change the pressure; Change other parameters.

Contents of No. 36 principle "phase transitions: Make use of phenomena taking place during phase transitions (volume changes, heat loss, etc.) 


\section{(3) Thinking and improvement}

First, No. 1 principle "segmentation" should be taken into consideration to allow the functionality of each part of the system to reach the optimum state (local). We can change the original single nozzle into several nozzles. Next, by following No. 19 principle "periodic action" should be considered to control the nozzles to work at the optimal time and period. It is recommended to introduce a certain nozzles to set the optimal flush angle to clean the whole urinal area by using minimal water volume.

Finally, No. 36 principle "phase transitions". It is a very important and useful concept. When phase of water transited from liquid to gaseous state or interphase, the water saving is very significant, and the cleaning area of each flush also bigger than before.

\section{TABLE 1. CONTRADICTION MATRIX OF} URINALS

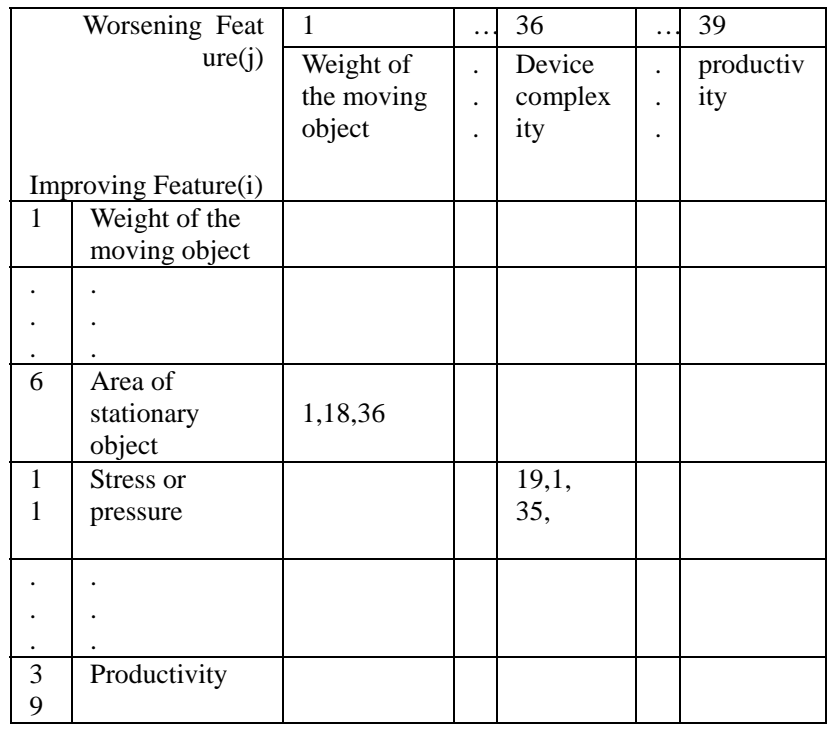

Synthesizing the outcome of 9-Windows and previous innovation principles, we redesign original structure of the urinal to a new one shown as Fig. 2.

\section{IV.CONCLUSIONS}

TRIZ innovation theory can be applied in a lot of things, not just only products but also service. Regardless of what the industry, problems will arise inevitably. The understanding and learning of TRIZ is like the opening of an extra window, and you can have a wider vision than others. It can guide us to quickly find where the problem lies, to analyze problems, identify the key, and then employ the thinking logic of TRIZ before taking appropriate solutions. In this study we apply TRIZ Systematic Innovation Method includes: 9-Windows, Contradiction Matrix, and 40 Inventive Principles to solve the problem. The final result shows that the improved urinal flusher devices can be used to adjust the angle to change the spraying angle of the wall of the urinal. We add adjustable nozzles to the urinal and really get good results. The most significant efficiency is each flush amount reduced from $1200 \mathrm{ml}$ to $300 \mathrm{ml}$ that means the water saving efficiency up to $75 \%$.

\section{REFERENCES}

[1] F. I. Kubota and L. C. da Rosa, "Identification and conception of cleaner production opportunities with the theory of inventive problem solving,” Journal of Cleaner Production, vol. 47, 2013, pp. 199-210.

[2] Amanda Bligh, “The Overlap Between TRIZ and Lean”, IME 552: Lean Manufacturing Systems, University of Rhode Island, March, 2006.

[3] Darrell Mann "Hands-On Systematic Innovation For Business \& Managers”, IFR press, 2007, pp.4-5.

[4] Darrell Mann "Hands-On Systematic Innovation For Business \& Managers”, IFR press, 2007, pp.117-119.

[5] Dana W. and Clarke, Sr. "40 Principles Extended Edition: TRIZ Keys to Technical Innovation”, Technical innovation center, 2005, pp.11-13.

[6] Dana W. and Clarke, Sr. "40 Principles Extended Edition: TRIZ Keys to Technical Innovation”, Technical innovation center, 2005, pp.17-18.
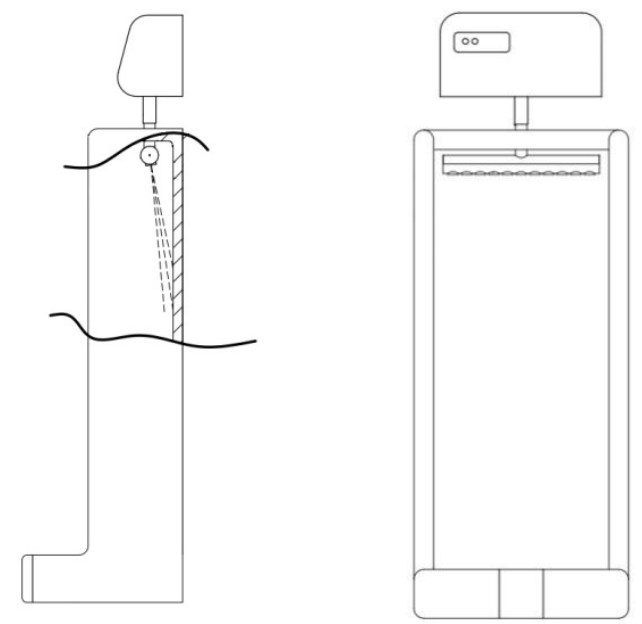

Figure 2. Improved structure of a urinal 